\title{
Genetic testing for Spinocerebellar Ataxias (SCA) in Parkinsonism
}

\author{
MD SIDDIQUR RAHMAN ${ }^{1}$, YOSHITAKANAGAI ${ }^{2}$, HAKIKO POPIEL $^{3}$, \\ MUZAHED UDDIN AHMED ${ }^{4}$, MD JALAL UDDIN $^{5}$, TALSUSHI TODA ${ }^{6}$
}

\begin{abstract}
:
Objective: The study was conducted to find out Spinocerebellar Ataxias (SCA) by genetic analysis from those presenting with parkinsonism in the Neurology department of Mymensingh Medical College. Materials and methods: A sample of about $5 \mathrm{ml}$ blood was collected by venipuncture in EDTA tube with informed consent from the patients following institutional ethics committee approval by genetic study from 7 healthy people and 9 patients. The neurological disorder along with a complete physical and/or psychological, as well as family history and demographic data was recorded with a prescribed questionnaire by the neurologists of Mymensingh Medical College. Extraction of genomic DNA from the venous blood using FlexiGene DNA kit (Qiagen, Japan) was performed in Department of Medicine, Bangladesh Agricultural University, Mymensingh 2202, Bangladesh. The extracted DNA was stored and accumulated and then these DNA were sent to Division of Clinical Genetics, Department of Medical Genetics, Osaka University Medical School, Suita, Osaka 565 0871, Japan for PCR and further analysis. PCR amplification of the CAG repeat was performed for the SCA1, SCA2, SCA3, SCA6 loci using primers SCA1N-F1 and SCA1N-R1, SCA2-F1 and SCA2-R1, MJDF1 and MJDR1, SCA6-F1 and SCA6-R1, respectively. Results: SCA1 PCR of both healthy individual and suspected PD patients DNA is about 250 bp (no. of CAG repeats=36). SCA2 PCR products reveal the DNA products of about $150 \mathrm{bp}$ (no. of CAG repeats=23) except one patient that we suspected and it was sequenced and revealed 175bp (no. of CAG repeats $=30$ ). SCA3 PCR product size of both healthy individual and patient DNA is within about 250 (no. of CAG=11) to $300 \mathrm{bp}$ (no. of CAG repeats=28) except one patient which is about 320bp and its CAG repeats is about 34. SCA6 PCR product size of both healthy individual and patient DNA is about 150bp (no. of CAG=16). Conclusion: This is the first time from Bangladesh regarding the range of CAG repeats in patients as well as healthy individual.
\end{abstract}

Key words: Spinocerebellar ataxias (SCA), parkinsonism, genetic testing

\section{Introduction:}

The autosomal dominant spinocerebellar ataxias (SCAs) are a complex group of neurodegenerative disorders characterized by progressive cerebellar ataxia of gait and limbs variably associated with ophthalmoplegia, pyramidal and extrapyramidal signs, dementia, pigmentary retinopathy and peripheral neuropathy ${ }^{1}$. There are several subtypes of SCAs: SCA1, SCA2, Machado-Joseph disease (MJD)/SCA3, SCA6, SCA7, SCA17 (Table 2). In all cases, expansion of CAG/ repeats in the respective genes have been implicated in the pathogenesis of the disease ${ }^{2-10}$. For example, the number of CAG repeats at the SCA1 locus varies

1. Professor, Department of Medicine \& Director, Veterinary Clinic, Bangladesh Agricultural University, Mymensingh 2202, Bangladesh and former JSPS Postdoctoral fellow, Division of Clinical Genetics, Department of Medical Genetics, Osaka University Medical School, 2-2-B9 Yamadaoka, Suita, Osaka 565-0871, Japan.

2. Associate Professor, Division of Clinical Genetics, Department of Medical Genetics, Osaka University Medical School, 2-2-B9 Yamadaoka, Suita, Osaka 565-0871, Japan.

3. Postdoctoral fellow, Division of Clinical Genetics, Department of Medical Genetics, Osaka University Medical School, 2-2-B9 Yamadaoka, Suita, Osaka 565-0871, Japan.

4. Ex Professor, Department of Medicine, Bangladesh Agricultural University, Mymensingh 2202, Bangladesh.

5. Assistant Professor, Department of Neurology, Mymensingh Medical College, Mymensingh 2200, Bangladesh*

6. Professor and Chairman, Department of Medical Genetics, Osaka University, School of Medicine, Japan. 
from 25 to 36 in normal individuals, while among affected individuals the range is 40 to $81^{5}$. Similarly, polymorphic CAG repeats in the ataxin2 gene (SCA2 locus) varies from 15 to 29 repeats among normal individuals and from 35 to 59 among affected individuals ${ }^{3,9}$.

Wide global variation in relative prevalence of SCA subtypes among autosomal dominant cerebellar ataxia (ADCA) patients has been observed. SCA1 has been reported to be far more common in Russia $^{11}$ than any other SCA subtypes. Recently Takano et $\mathrm{al}^{12}$ have reported that the general prevalence of SCA1 and SCA2 is significantly higher among white SCA pedigrees (15\% and 14\%, respectively) than in the Japanese (3\% and 5\% respectively), whereas relative prevalence of SCA3 is higher in the Japanese pedigrees (43\%) than in whites (30\%). Also, SCA6 appear to be less frequent in white populations (5\%) than in Japanese populations (11\%) respectively ${ }^{12}$ It has been reported that SCA2 is exclusively responsible for all ataxia cases in the Indian population ${ }^{13}$. In a study of six Indian SCA2 pedigrees, Wadia et al ${ }^{13}$ observed CAG repeat expansion in 14 affected family members at the SCA2 locus. All of these patients showed slow saccades and peripheral neuropathy. An inverse correlation between repeat size and age at onset was observed with repeat numbers varying from 36 to 45 repeats $^{13}$. Similar observation has been reported by Saleem et al ${ }^{14}$ in an independent set of 39 SCA pedigrees principally from northern India. SCA2 is also the most common form of hereditary ataxias among Korean patients ${ }^{15}$, constituting $12.6 \%$ of all SCA patients, followed by SCA6 (6.9\%) and SCA3 (4.6\%).

SCA3 is more common in Germany ${ }^{16}$, Brazil ${ }^{17}$ United States ${ }^{18,19}$, Portugal ${ }^{20}$ and Japan ${ }^{21}$. In Portugal, expansion at SCA3/MJD locus was observed in 74\% of ADCA patients, followed by expansion at SCA2 locus in $4 \%$ of patients. The investigators did not find any SCA1, SCA6 mutation $^{20}$. Similarly, in the Japanese population, Sasaki and Tashiro ${ }^{21}$ have observed that $24.6 \%$ of patients possessed CAG expansion at the SCA3 locus, followed by expansions at SCA6 (11.8\%), SCA1 (10.5\%) and SCA2 (4.4\%) loci. SCA6 is the most common (5\%) expansion mutation in SCA patients in the United Kingdom, followed by SCA2 ${ }^{22}$. Expansion at the SCA6 locus is also very frequent (13\%) in ADCA families of Germany ${ }^{23}$. Spinocerebellar ataxia type 3 (SCA3), can present with parkinsonism. However, classically, atypical features, including pyramidal and cerebellar signs, peripheral neuropathy, and/or anterior horn cell dysfunction, are also seen ${ }^{24}$. To our knowledge, there are no previous reports of regarding the CAG repeat in patients as well as healthy individuals in Bangladesh. In this study we present the results of DNA analysis of CAG repeats in the healthy individual and as well as patients provisionally diagnosed as Parkinson Disease (PD) in Department of Neurology, Mymensingh Medical College, Mymensingh-2200, Bangladesh.

\section{Materials and Methods:}

A sample of about $5 \mathrm{ml}$ blood was collected by venipuncture in EDTA tube with informed consent from the patients following approval by institutional ethics committee for genetic study from 7 healthy people and 9 patients who came to Department of Neurology, Mymensingh Medical College, Mymensingh 2200, Bangladesh. The neurological disorder along with a complete physical and/or psychological, as well as family history and demographic data (sex, age at onset, age at referral, residence) was recorded with a prescribed questionnaire by the neurologists of Mymensingh Medical College. Extraction of genomic DNA from the venous blood using FlexiGene DNA kit (Qiagen, Japan) was performed in Department of Medicine, Bangladesh Agricultural University, Mymensingh 2202, Bangladesh. Briefly, pipetting of $7.5 \mathrm{ml}$ Buffer FG1 into a $15 \mathrm{ml}$ centrifuge tube and then adding of $3 \mathrm{ml}$ whole blood and mixing by inverting the tube 5 times. Centrifuging for $5 \mathrm{~min}$ at $2000 \mathrm{xg}$ in a swing-out rotor and discarding the supernatant and leaving the tube inverted on a clean piece of absorbent paper for 2 min, taking care that the pellet remains in the tube. Adding of $1.5 \mathrm{ml}$ Buffer FG2, closing the tube, and vortexing immediately until the pellet is completely homogenized. Inverting the tube 3 times, placing it in a heating block or water bath, and incubate at 65 degree $\mathrm{C}$ for 10 min. Adding of $1.5 \mathrm{ml}$ isopropanol (100\%) and 
mixing thoroughly by inversion until the DNA precipitate becomes visible as thread or a clump and centrifuging for $3 \mathrm{~min}$ at $2000 \mathrm{xg}$. Discarding the supernatant and briefly invert the tube onto a clean piece of absorbent paper, taking care that the pellet remains in the tube. Adding of $1.5 \mathrm{ml}$ $70 \%$ ethanol and vortex for 5 second and centrifuging for $3 \mathrm{~min}$ at $2000 \mathrm{x}$ g. Discarding of the supernatant and leaving the tube inverted on a clean piece of absorbent paper for at least $5 \mathrm{~min}$, taking care that the pellet remains in the tube. Airdrying the DNA pellet until all the liquid has evaporated and adding 300 microliter FG3, vortexing for 5 second at low speed, and dissolve the DNA by incubating for 1 hour at 65 degree $C$ in a heating block or water bath and stored at -70 degree $C$ until used.
The extracted DNA was stored and accumulated and then these DNA were sent to Division of Clinical Genetics, Department of Medical Genetics, Osaka University Medical School, Suita, Osaka 565 0871, Japan for PCR and further analysis. PCR amplification of the CAG repeat was performed for the SCA1, SCA2, SCA3, SCA6 loci using primers SCA1N-F1 and SCA1N-R1, SCA2-F1 and SCA2R1, MJDF1 and MJDR1, SCA6-F1 and SCA6-R1, respectively (Table 1 ) and the condition for amplification were essentially same as described earlier $4,6,9,10,25$. PCR products were checked in $3 \%$ agarose gel and the sequencing of the suspected PCR products were performed using Genescan system (version 2.02) in an ABI-377 automated DNA sequencer.

Table-I

PCR Primer Sequences used in this study for detection of SCA1, SCA2, SCA3, SCA6 loci.

\begin{tabular}{ll}
\hline Primer & Sequences \\
\hline SCA1N-F1 & CTG GCC AACATG GGC AGT CTG AG \\
SCA1N-R1 & GGA GAACTG GAAATG TGG ACG TA \\
SCA2-F1 & CCC TCA CCA TGT CGC TGAAGC \\
SCA2-R1 & CGACGC TAG AAG GCC GCT G \\
MJD-F1 & CCAGTG ACT ACT TTG ATT CG \\
MJD-R1 & CTT ACC TAG ATC ACT CCC AA \\
SCA6-F1 & CAC GTG TCC TAT TCC CCT GTG ATC C \\
SCA6-R1 & TGG GTACCT CCG AGG GCC GCT GGT G \\
\hline
\end{tabular}

Table-II

Different types of SCA with its gene range of CAG repeat and affected regions.

\begin{tabular}{|c|c|c|c|c|}
\hline \multirow[t]{2}{*}{ Diseases } & \multirow[t]{2}{*}{ Gene } & \multicolumn{2}{|c|}{ CAG repeat } & \multirow[t]{2}{*}{ Affected regions } \\
\hline & & Normal & Disease & \\
\hline spinocerebellar ataxia type 1 (SCA1) & ataxin-1 & $6-44$ & $39-83$ & $\begin{array}{l}\text { Cerebellar Purkinje cells, dentate } \\
\text { nucleus, brainstem }\end{array}$ \\
\hline spinocerebellar ataxia type 2 (SCA2) & ataxin-2 & 15-31 & $36-63$ & Cerebellar Purkinje cells, brainstem \\
\hline $\begin{array}{l}\text { spinocerebellar ataxia type } 3 \text { (SCA3) } \\
\text { /Machado-Joseph disease }\end{array}$ & ataxin-3 & $12-41$ & $55-84$ & $\begin{array}{l}\text { Dentate nucleus, basal ganglia, } \\
\text { brainstem, spinal cord }\end{array}$ \\
\hline spinocerebellar ataxia type 6 (SCA6) & $\begin{array}{l}\text { ? } 1 \text { A calcium } \\
\text { channel }\end{array}$ & $4-18$ & $21-33$ & Cerebellar Purkinje cells \\
\hline spinocerebellar ataxia type 7 (SCA7) & ataxin-7 & 4-35 & $37-306$ & Cerebellar, brainstem, retina \\
\hline spinocerebellar ataxia type 17 (SCA17) & $\begin{array}{l}\text { TATA-binding } \\
\text { protein }\end{array}$ & $25-44$ & $46-63$ & $\begin{array}{l}\text { Cerebellar, cerebral cortex, } \\
\text { basal ganglia }\end{array}$ \\
\hline
\end{tabular}




\section{Results and Discussion:}

SCA1 PCR of both healthy individual and suspected PD patients DNA is about 250 bp (no. of CAG repeats=36) (Figure 1). SCA2 PCR products reveal the DNA products of about $150 \mathrm{bp}$ (no. of CAG repeats $=23$ ) (Figure 2) except one patient that we suspected and it was sequenced and revealed 175bp (no. of CAG repeats=30) (Figure 3). SCA3 PCR product size of both healthy individual and patient DNA is within about 250 (no. of $C A G=11$ ) to $300 \mathrm{bp}$ (no. of CAG repeats=28) except one patient which is about $320 \mathrm{bp}$ and its CAG repeats is about 34 (Figure 4). SCA6 PCR product size of both healthy individual and patient DNA is about 150bp (no. of $C A G=16$ ) (Figure 5).

The polyglutamine diseases are a group of inherited neurodegenerative diseases caused by the expansion of a CAG repeat coding for glutamine in each disease-causing gene. Currently there is no effective treatment against the polyQ diseases. In
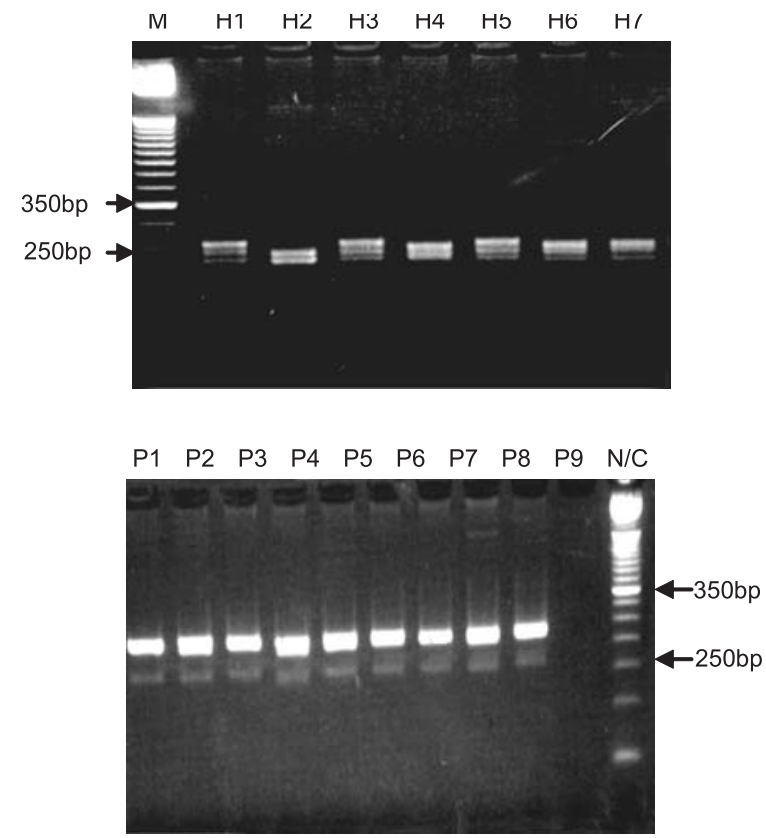

Fig.-1: SCA1 PCR of 7 healthy individuals DNA (above) and 9 patients DNA (below): the PCR product size of both healthy $(\mathrm{H} 1-\mathrm{H} 7)$ and patient DNA (P1-P9) is about 250bp (no. of CAG repeats $=36$ ) and therefore revealed no difference between the healthy individual and patient DNA, $N / C=$ negative control, $M=$ molecular marker .
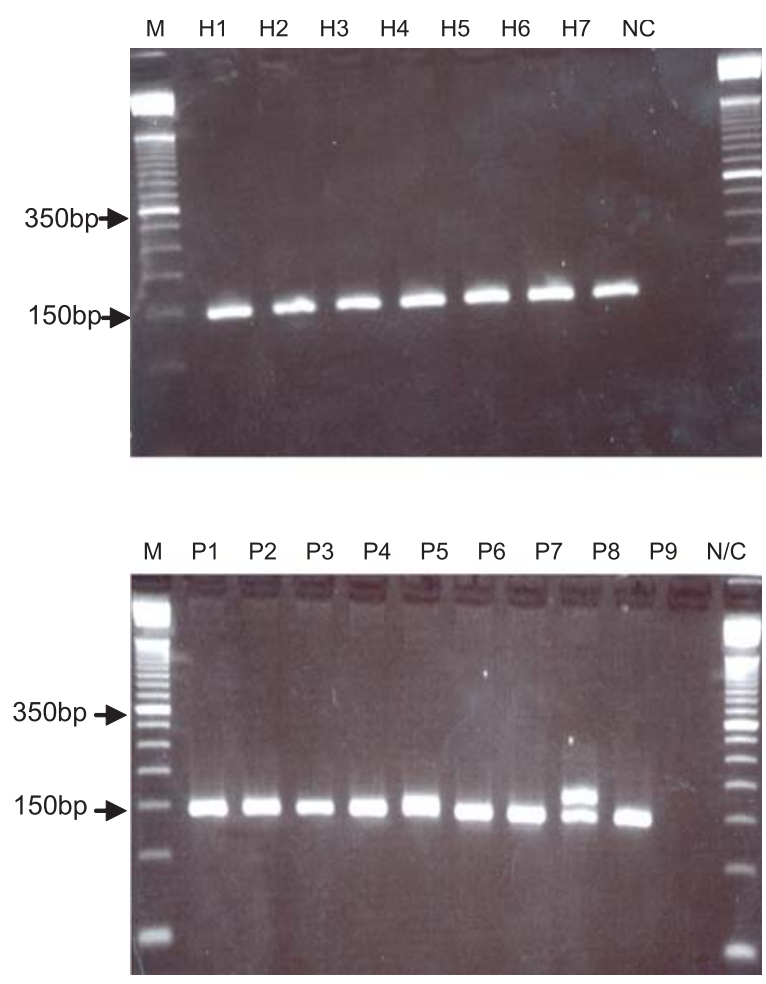

Fig.-2: SCA2 PCR of 7 healthy individuals DNA (above) and 9 patients DNA (below): the PCR product size of both healthy $(\mathrm{H} 1-\mathrm{H} 7)$ and patient (P1-P9) DNA is about 150bp (no. of CAG repeats $=23$ ) except no. 8 of patient sample which is about 175bp and this product was sequenced and it revealed 30 CAG repeats that is within the normal range, $N / C=$ negative control, $M=$ molecular marker.

the pathogenesis of the polyQ diseases, expansion of the polyQ stretch is thought to cause misfolding of the protein, resulting in pathogenic protein-protein interactions including aggregate formation, leading to neuronal dysfunction and eventual neuronal death. Although extensive research has been performed regarding polyQ-mediated neuronal cell death, recent detailed analyses of brains of polyQ disease patients as well as mouse models have revealed that neuronal phenotypes develop before marked cell death is observed ${ }^{26}$. SCA is one of several polyglutamine diseases.

The first genetically documented family with MJD (SCA3) in India was reported by Chakravarty et $\mathrm{al}^{27}$ 


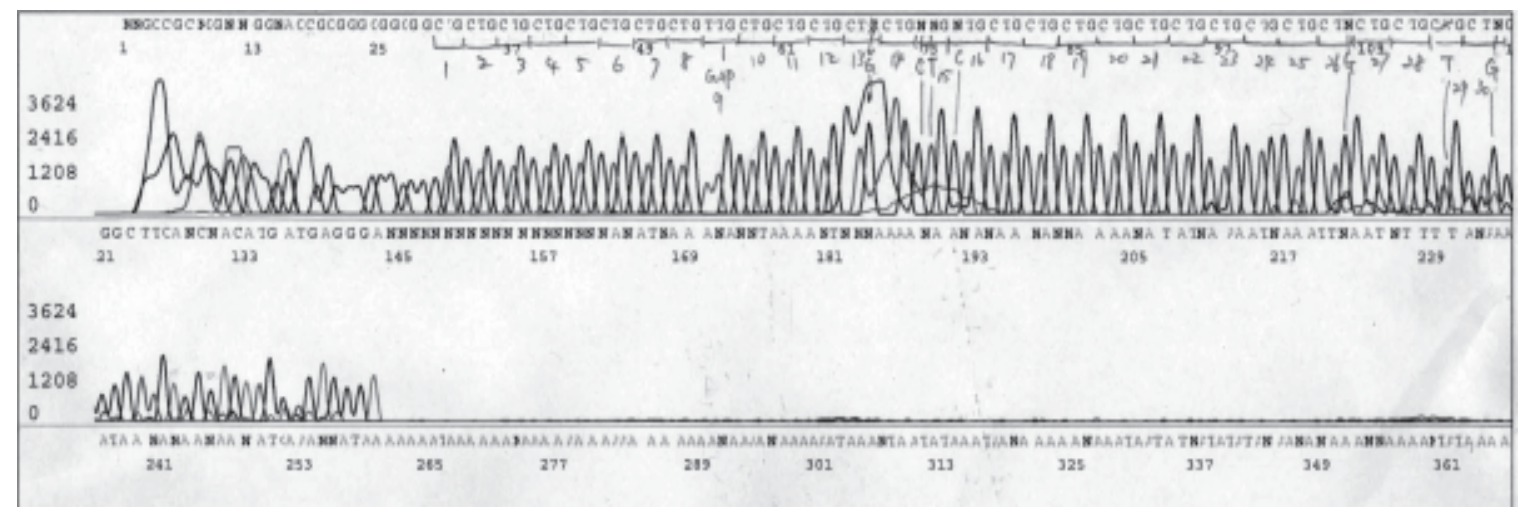

Fig.-3: Sequenced data SCA2 PCR products from one patient (patient no. 8 that was suspected of SCA2 and it revealed $175 b p$ (no. of CAG repeats $=30$ ).
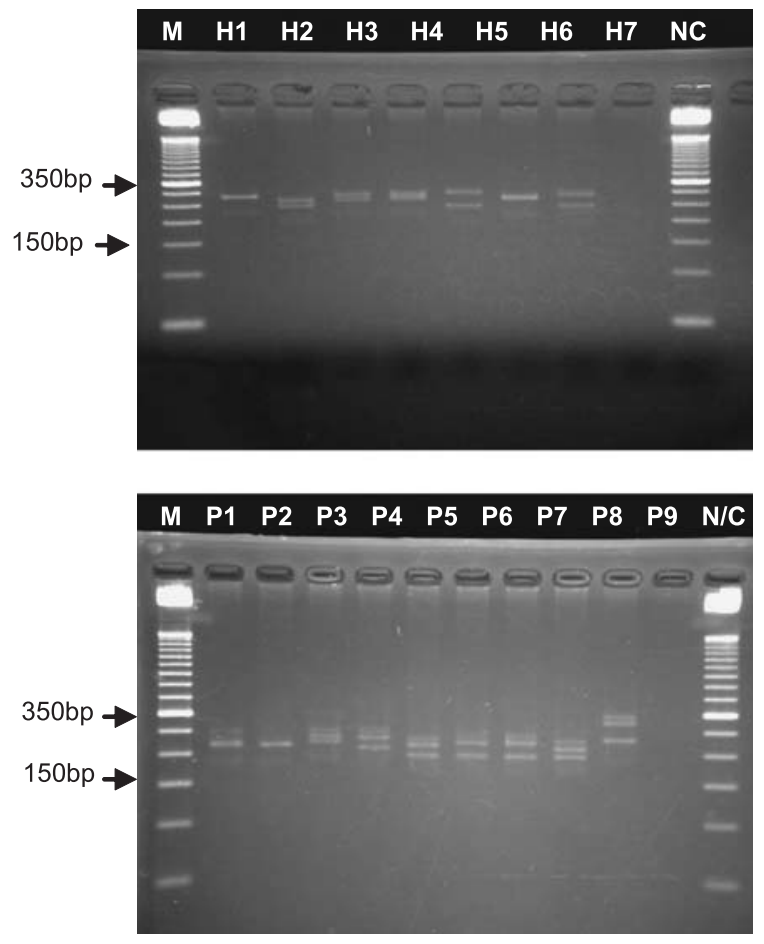

Figure 4: SCA3 PCR of 7 healthy individuals DNA (above) and 9 patients DNA (below): the PCR product size of both healthy (H1-7) and patient (P1-P9) DNA is within about 250 (no. of CAG repeats $=11$ ) to $300 \mathrm{bp}$ (no. of CAG repeats $=28$ ) except no. 9 of patient which is about 320bp and its CAG repeats no. is about 34 that not pathogenic (pathogenic range is 62-79 in India), N/C= negative control, $M=$ molecular marker.
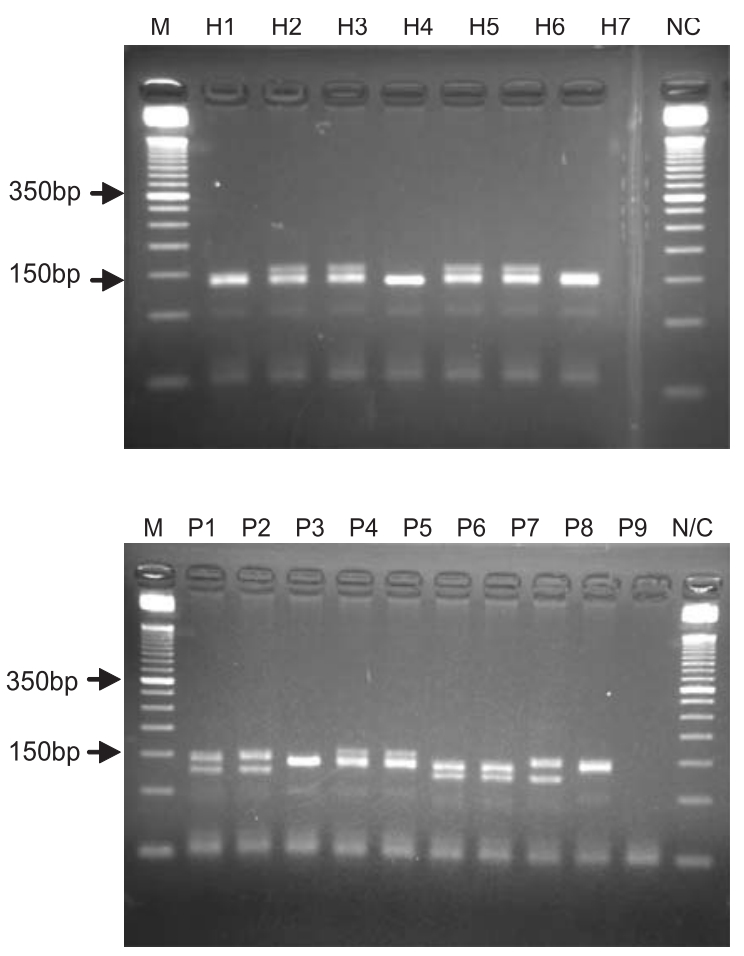

Fig.-5: SCA 6 PCR of 7 healthy individuals DNA (above) and 9 patients DNA (below): the PCR product size of both health $(\mathrm{H} 1-\mathrm{H} 7)$ and patient DNA (P1-P9) is about 150bp (no. of CAG repeats $=16)$ and therefore revealed no difference between the control and patient DNA, N/C= negative control, $M=$ molecular marker. 
in 1996 among Bengali family. Subsequently, genetic studies in families with cerebellar ataxias have been made by Wadia et al ${ }^{13,28}$ in Mumbai and Sinha at Ranchi ${ }^{29}$ and updated reviews on the subject have been written by Sinha ${ }^{30}$, Banerjee and Chakravarty ${ }^{31}$ and Wadia ${ }^{32}$. More recently two multiauthored communications highlighted on the molecular genetic aspects of autosomal dominant herediatary ataxias in India including Bengali family ${ }^{14,33}$. Basu et al ${ }^{33}$ detected CAG repeat expansion in 6 patients $(10.5 \%)$ at the SCA1 locus (range of expanded CAG repeat no. 44-52), ten of the 57 patients (17.5\%) had CAG repeat expansion at the SCA2 locus (range of expanded CAG repeat no. 39-45), while four (7\%) had CAG expansion at the SCA3/MJD locus (range of expanded CAG repeat no. 62-79) and at the SCA6 locus there was a single patient (1.8\%) with 21 CAG repeats. Ghosh et $\mathrm{al}^{34}$ reported five ethnic Bengali subjects with positive family history and found 3 cases of SCA1, 2 with SCA3 mutation and none with SCA2. Chakravarty and Mukherjee ${ }^{35}$ also reported SCA in Ethnic Bengali; 2 families with SCA1, 4 families with SCA2, 5 families with SCA3 but there are no reports yet from Bengali population in Bangladesh (peoples in Bangladesh \& West Bengal, a State of India are known as Bengali).

Bangladesh and India are in the same geographical region and it was the same country until the year 1947 but the people are not necessarily genetically akin. In this study we had examined 7 healthy individual in Mymensingh and 9 patients who came to the neurologists of Mymensingh Medical College and were diagnosed as Parkinson Disease. The age group of all the patients were 57-80 and all the patients has the tremor and most of patients has the tendency to fall down and memory impairment. Spinocerebellar ataxia type 3 (SCA3), can present with parkinsonism. However, classically, atypical features, including pyramidal and cerebellar signs, peripheral neuropathy, and/or anterior horn cell dysfunction, are also seen ${ }^{24}$. The patients diagnosed as PD were both male and female and they have other complaints but all are diagnosed as PD by the neurologists in Mymensingh Medical College.
The SCA1 PCR product size of both healthy individual and patient DNA is about 250bp (no. of CAG repeats $=29$ ) and therefore revealed no difference between the healthy individual and patient DNA. The SCA2 PCR product size of both healthy individual and patient DNA is about 150bp (no. of CAG repeats $=23$ ) except no. 8 of patient sample which is about $175 \mathrm{bp}$ and this product was sequenced and it revealed 30 CAG repeats that is within the normal range. The SCA3 PCR product size of both healthy individual and patient DNA is within about 250 (no. of CAG repeats $=11$ ) to $300 \mathrm{bp}$ (no. of CAG repeats $=28$ ) except no. 9 of patient which is about $320 \mathrm{bp}$ and its CAG repeats no. is about 34 but not pathogenic (pathogenic range is 62-79 in India). The SCA6 PCR product size of both healthy individual and patient DNA is about $150 \mathrm{bp}$ (no. of CAG repeats=16) and therefore revealed no difference between the healthy individual and patient DNA.

Spinocerebellar ataxia type 3 (SCA3), can present with parkinsonism but has not been previously reported, to our knowledge from Bangladesh. However, atypical, though also levodoparesponsive, parkinsonism has been previously reported to occur in African American families, suggesting that that this phenotype is associated with African ancestry. In this regard, it is perhaps significant that all the individuals with parkinsonism have relatively low numbers of repeats (normal, 1634; pathologic, 60-84). In families in which linkage analysis is being performed to determine a locus for autosomal dominant parkinsonism suggestive of $\mathrm{PD}$, evaluation for the MJD/SCA3 mutation is indicated. In our study in Bangladesh we never recorded any CAG repeat within the pathological ranges. This is the first time from Bangladesh regarding the range of CAG repeats in patients as well as healthy individual.

\section{Acknowledgements:}

The first author was financed by Japan Society for the Promotion of Science (JSPS) as JSPS (06252) Postdoctoral fellow, Japan at Division of Clinical Genetics, Department of Medical Genetics, Osaka University Medical School, 2-2-B9 Yamadaoka, Suita, Osaka 565-0871, Japan 


\section{References:}

1. Zoghbi HY, Orr HT. Glutamine repeats and neurodegeneration. Annu Rev Neurosci 2000; 23:217-47.

2. David G, Abbas N, Stevanin G, Durr A, Yvert $G$, Cancel $G$, et al. Cloning of the SCA7 gene reveals a highly unstable CAG repeat expansion. Nat Genet 1997; 17:65-70.

3. Imbert G, Frederic S, Yvert G, Devys D, Trottier $\mathrm{Y}$, Garnier J-M. Cloning of the gene for spinocerebellar ataxia 2 reveals a locus with high sensitivity to expanded CAG/glutamine repeats. Nat Genet 1996; 14:285-91.

4. Kawaguchi Y, Okamoto T, Taniwaki M, Aizawa $M$, Inoue $M$, Katayama $S$, et al. CAG expansions in a novel gene for MachadoJoseph disease at chromosome 14q32.1. Nat Genet 1994; 8:221-8.

5. Orr HT, Chung M, Banfi S, Kwiatkowski TJ, Servadio A, Beaudet AL. Expansion of an unstable trinucleotide CAG repeat in spinocerebellar ataxia type1. Nat Genet 1993; 4:221-6.

6. Koide R, Ikeuchi T, Onodera O, Tanaka H, Igarashi S, Endo K. Unstable expansion of CAG repeat in hereditary dentatorubralpallidoluysian atrophy (DRPLA). Nat Genet 1994; 6:14-18.

7. Koob MD, Moseley ML, Schut LJ, Benzow, KA, Bird TD, Day JW. An untranslated CTG expansion causes a novel form of spinocerebellar ataxia (SCA8). Nat Genet 1999; 21:379-84.

8. Pulst S-M, Nechiporuk A, Nechiporuk T, Gispert S, Chen X-N, Lopes-Cendes I. Moderate expansion of a normally biallelic trinucleotide repeat in spinocerebellar ataxia type 2. Nat Genet 1996; 14:269-76.

9. Sanpei K, Takano H, Sato T, Oyake M, Sasaki $H$, Wakisaka A. Identification of the spinocerebellar ataxia type 2 gene using a direct identification of repeat expansion and cloning technique, DIRECT. Nat Genet 1996; 14:227-84.
10. Zhuchenko O, Bailey J, Bonnen P, Ashizawa T, Stockton DW, Amos C. Autosomal dominant cerebellar ataxia (SCA6) associated with small polyglutamine expansions in the $1 \mathrm{~A}$-voltagedependent calcium channel. Nat Genet 1997; 15:62-9.

11. Illarioshkin SN, Slominsky PA, Ovchinnikov IV, Markova ED, Miklina NI, Klyushnikov SA, Spinocerebellar ataxia type 1 in Russia. J Neurol 1996; 243:506-10.

12. Takano H, Cancel G, Ikeuchi T, Lorenzetti $D$, Mawad R, Stevanin G. Close associations between prevalences of dominantly inherited spinocerebellar ataxias with CAG-repeat expansions and frequencies of large normal CAG alleles in Japanese and Caucasian populations. Am J Hum Genet 1998; 63: 1060-66.

13. Wadia N, Pang J, Desai J, Mankodi A, Desai M, Chamberlain S. A. Clinicogenetic analysis of six Indian spinocerebellar ataxia (SCA2) pedigrees, the significance of slow saccades in diagnosis. Brain 1998; 121:2341-5.

14. Saleem Q, Choudhury S, Mukherji M, Bashyam L, Padma MV, Chakravarthy A. Molecular analysis of autosomal dominant hereditary ataxias in the Indian population: high frequency of SCA2 and evidence for a common founder mutation. Hum Genet 2000; 106:179-87.

15. Jin DK, Oh MR, Song SM, Koh SW, Lee M, Kim GM. Frequency of spinocerebellar ataxia types 1:2:3:6:7 and dentatorubral pallidoluysian atrophy mutations in Korean patients with spinocerebellar ataxia. J Neurol 1999; 246:207-10.

16. Schöls L, Vieira-Saecker AM, Schöls S, Przuntek H, Eppen JT, Reiss O. Trinucleotide expansion within the MJD1 gene presents clinically as spinocerebellar ataxia and occurs most frequently in German SCA patients. Hum Mol Genet 1995; 4:1001-05.

17. Lopes-Cendes I, Teive HG, Calcagnotto ME, Da Costa JC, Cardoso F, Viana E. Frequency of the different mutations causing 
spinocerebellar ataxia (SCA1, SCA2, MJD/ SCA3 and DRPLA) in a large group of Brazilian patients. Arq Neuropsiquiatr 1997; 55:519-29.

18. Geschwind DH, Perlman S, Figueroa CP, Treiman LJ, Pulst SM. The prevalence and wide clinical spectrum of the spinocerebellar ataxia type 2 trinucleotide repeat in patients with autosomal dominant cerebellar ataxia. Am J Hum Genet 1997; 60: 842-50.

19. Moseley ML, Benzow KA, Schut LJ, Bird TD, Gomez CM, Barkhaus PE. Incidence of dominant spinocerebellar and Friedreich triplet repeats among 361 ataxia families. Neurology 1998; 51:1666-71.

20. Silveira I, Coutinho P, Maciel P, Gaspar C, Hayes S, Dias A. Analysis of SCA1, DRPLA, MJD, SCA2 and SCA6 CAG repeats in 48 Poruguese ataxia famalies. Am J Med Genet 1998; 28:134-8.

21. Sasaki H, Tashiro K (1999). Frequencies of triplet repeat disorders in dominantly, inherited spinocerebellar ataxia (SCA) in the Japanese. Nippon Rinsho 2000; 57:21-5.

22. Leggo J, Dalton A, Morrison PJ, Dodge A, Connarty $M$, Kotze $M J$, et al. Analysis of spinocerebellar ataxia types 1:2:3, and 6 , dentatorubral-pallidoluysian atrophy, and Friedreich's ataxia genes in spinocerebellar ataxia patients in the UK. J Med Genet 1997; 34:982-5.

23. Schöls L, Kruger R, Amoiridis G, Przuntek H, Epplen JT, Riess O. Spinocerebellar ataxia 6: genotype and phenotype in German kindreds. J Neurol Neurosurg Psychiatry 1998; 64: 67-73.

24. Katrina $\mathrm{GH}$, Andrew $\mathrm{S}$, Padraig $\mathrm{O}$, Michael B, David N, Amanda A, et al. Spinocerebellar Ataxia Type 3 Phenotypically Resembling Parkinson Disease in a Black Family. Arch Neurol. 2001; 58:296-9.

25. Stevanin G, Guinti P, Davia G, Balal S, Durr $A$, Ruberg $M$. De novo expansion of intermediate alleles in spinocerebellar ataxia 7. Hum Mol Genet 1998; 7:1809-13.
26. Yamamoto A, Lucas JJ, Hen R. Reversal of neuropathology and motor dysfunction in a conditional model of Huntington's disease. Cell. 2000; 101(1): 57-66.

27. Chakravarty A, Mukherjee A, Banerjee S, Saleem Q. Hereditary ataxia with ophthalmoplegia - preliminary observations on a Bengalee family with autosomal dominant inheritance. J Assoc neuroscientists Eastern India. 1996; 1:188-98.

28. Peng J, Allotey R, Wadia NH. A common disease haplotype segregating in spinocerebellar ataxia 2 (SCA2) pedigress of diverse ethnic origin. Eur J Hum Genet 1999; 7:841-5.

29. Sinha KK, Jha DK. A study of sporadic adult onset degenerative cerebellar ataxias. Ann Indian Acad Neurol 1999; 2:15-9.

30. Sinha KK. Clinical aspects of hereditary ataxias. Neurosciences Today 1997; 3 \& 4:175-84.

31. Banerjee S, Chakravarty A. Hereditary a faxias and the new genetics. In: MOHONDAS, $\mathrm{S}$, eds. Reviews in neurology. Hyderabad: Indian Academy of Neurology 1997: 145-61.

32. Wadia NH. Cerebellar disorders. In: SAINANI GS, ed. API Text Book of Medicine. Mumbai: Association of Physicians of India 1999: 797-803.

33. Basu P, Chattopadhyay B, Gangopadhyay P. Analysis of CAG repeats in SCA1, SCA2, SCA3, SCA6, SCA7, and DRPLA loci in spinocerebellar ataxia patients and distribution of CAG repeats at the SCA1, SCA2 and SCA6 loci in nine ethnic populations of Eastern India. Hum Genet 2000; 106:597-604.

34. Ghosh B, Gangopadhyay PK, Saha S. Genetic study of adult onset inherited progressive ataxia. J Assoc Neuroscientists Eastern India 2000; 5:51-4.

35. Chakravarty A \& Mukherjee S. C.. Autosomal dominant cerebellar ataxias in ethnic Bengalees in West Bengal - an Eastern Indian state. Acta Neurol Scand 2002; 105(3): 202-8. 